\title{
Carcinoma triquilemal: relato de um caso
}

\section{Trichilemmal carcinoma: case report}

\author{
Marcos Antônio Nemetz $z^{1}$, Regina Maria da Cunha ${ }^{2}$, \\ Priscilla Reeck ${ }^{2}$, Waldir Carreirão Neto ${ }^{2}$, Maria \\ Teresa S. Moreira ${ }^{3}$, Marina S. Coelho ${ }^{4}$
}

\section{Resumo / Summary}

\footnotetext{
C
} rcinoma triquilemal é uma lesão maligna de baixo grau, pouco freqüente, que se origina de célula do folículo piloso, sendo necessário o diagnóstico diferencial com outros carcinomas de pele. O objetivo do trabalho é relatar um caso de carcinoma triquilemal atendido no ambulatório de Otorrinolaringologia e Cirurgia de Cabeça e Pescoço da Universidade Regional de Blumenau, em um paciente feminino de 86 anos que apresentou lesão em região supraclavicular esquerda, com um ano de evolução e crescimento progressivo, medindo $75 \times 45 \mathrm{~mm}$, vegetante, endurecida, avermelhada, friável, com ulceração central, secreção sanguinolenta e dor local. Foi realizada excisão do tumor com margens cirúrgicas livres. Devido ao curso da lesão geralmente não desenvolver metástases, nem recorrência local, optou-se por não realizar terapia adjuvante, apenas acompanhamento periódico da lesão.
Palavras-chave: carcinoma triquilemal.

Key words: trichilemmal carcinoma. richilemmal carcinoma is a malignant lesion of low degree, not so frequent, that originates from a hair follicle cell, being necessary a special diagnosis in relation to others skin carcinomas. The aim of this issue is to relate a case of trichilemmal carcinoma dealt in the sickroom of Otorrinolaringologia and Head and Neck Surgery from "Universidade Regional de Blumenau" in a male 86-yearpatient, that had a lesion in a left supra-clavicle region with a year of evolution and progressive growth, measuring $75 \times 45 \mathrm{~mm}$, vegetate, hardened, reddish, with a central ulceration, blood secretion and local pain. The tumor was removed surgically with free limits. Due to the type of lesion generally nor develops metastases, neither has local recidivation, it was decided for not realizing concomitant therapy only periodical inquiring of the lesion.

\footnotetext{
${ }^{1}$ Professsor da disciplina de Otorrinolaringologia e Cirurgia de Cabeça e Pescoço da Universidade Regional de Blumenau.

${ }^{2}$ Médica e estagiária do serviço de Cirurgia de Cabeça e Pescoço da Universidade Regional de Blumenau.

Acadêmico(a) do $6^{\circ}$ ano de Medicina da Universidade Regional de Blumenau.

${ }^{4}$ Acadêmica do $4^{\circ}$ ano de Medicina da Universidade Regional de Blumenau

Endereço para correspondência: Marcos Antônio Nemetz - Rua Heloi Dalssasso 345 89030-230.

Tel (0xx47) 326-3790/ 326-0417/ 9983-0417.

Artigo recebido em 03 de julho de 2003. Artigo aceito em 08 de agosto de 2003.
} 


\section{INTRODUÇÃO}

Carcinoma triquilemal é uma lesão pouco freqüente, considerada maligna, cuja baixa ocorrência de recidiva e raras metástases o fazem ser considerado carcinoma de baixo grau de malignidade.

Origina-se de células do folículo piloso e é sempre necessário estabelecer o diagnóstico diferencial com outros carcinomas de pele.

Relatamos um caso de carcinoma triquilemal em uma mulher de 86 anos, bem como alguns aspectos da doença.

\section{REVISÃo DA LITERATURA E DIAGNÓSTICO DIFERENCIAL}

O termo carcinoma triquilemal (TLC) foi introduzido como entidade por Headington em 1976, porém, por muitos anos não foi adotado pelos patologistas ${ }^{1}$. Atualmente, a publicação de algumas séries contribuiu para distinguir os TLC de outros grupos de tumores foliculares.

Carcinoma triquilemal é um tumor raro, ocorre geralmente na pele exposta ao sol, em indivíduos entre a $4^{\underline{a}}$ e 9 ${ }^{a}$ décadas de vida. Os locais de predileção situam-se na face, couro cabeludo, pescoço e dorso das mãos ${ }^{2}$.

Van Vlotem et al. encontraram maior número de carcinomas em pacientes submetidos à irradiação para doenças benignas da cabeça e pescoço. Segundo o autor, apresenta longos períodos de latência e sua prevalência está diretamente relacionada com a dose de irradiação a que o paciente esteve submetido ${ }^{3}$.

As lesões podem se apresentar clinicamente como pápulas, nódulos ou placas, freqüentemente ulceradas ou com crostas. A coloração é geralmente avermelhada - "cor de carne" - normalmente medem de 0,5 a $2 \mathrm{~cm}$ seu maior diâmetro ${ }^{2}$. Usualmente solitários, sendo rara sua descrição na sua forma múltipla 3 . O diagnóstico pode ser estabelecido pela histologia simples e/ou imunohistoquímica da lesão.

Histologicamente, o tumor se apresenta puramente intraepitelial ou mais comumente associado a um componente invasivo, que pode se estender desde a epiderme até a gordura subcutânea. Comumente se mostram contínuos com a epiderme e o epitélio folicular. Quando grandes, apresentam focos de hemorragia e/ou necrose.

Quanto à imunohistoquímica do carcinoma triquilemal, é usualmente CEA e EMA negativo, entretanto sua positividade tardia é ocasionalmente documentada ${ }^{2}$.

O diagnóstico diferencial pode ser feito com carcinoma de células escamosas, carcinoma basocelular, queratoacantoma, melanoma nodular maligno. Entretanto, tais lesões são papulonodulares, geralmente se estendem à derme reticular, são propensas à recorrência local e freqüentemente dão metástases. Ao contrário, o carcinoma triquilemal apresenta um curso indolente, dificilmente ressurge após sua excisão ou desenvolve metástases em outros órgãos ${ }^{1}$.

\section{APRESENTAÇÃo DO CASO CLÍNICO}

C.K., 86 anos, do sexo feminino, viúva, natural de Rio do Sul (SC), procedente de Blumenau, ex-trabalhadora rural.

Paciente procurou o ambulatório da Universidade Regional de Blumenau, apresentando lesão de pele em região supraclavicular esquerda, avermelhada, pouco dolorosa, com crescimento progressivo tornado-se vegetante, friável, com dor local intermitente e um ano de evolução.

Nos últimos 10 anos foi submetida a exérese de carcinoma basocelular em região frontal direita, e de carcinomas espinocelulares em região pré-auricular direita, em região dorsal do nariz e em região clavicular esquerda, sendo esta última irradiada no pós-operatório.

Paciente com boa saúde, sem referir história previa de patologia sistêmica.

Ao exame, apresentava lesão em região supraclavicular esquerda com 75x45mm, endurecida, vegetante, avermelhada, dolorosa à palpação, ulcerada, com secreção sanguinolenta, aderida a planos profundos, acometendo a região da musculatura pré escalênica e sem déficit motor (Foto 1 e 2).

Foi instituído tratamento cirúrgico. Durante a cirurgia evidenciou-se tumor nodular infiltrante e ulcerado da pele do pescoço. A fossa clavicular esquerda estava acometida e encontrava-se congelada pela neoplasia. Foi realizada a remoção do periósteo da clavícula e dos músculos escalenos (Foto 3) e a reconstrução primária com rotação de retalho miocutâneo de peitoral maior pediculado na artéria mamária interna (Foto 4).

A paciente evoluiu bem e recebeu alta hospitalar no quinto dia pós-operatório.

Resultado do anatomopatológico da lesão: Macroscopia: Material representado por segmento de pele e tecido celular subcutâneo medindo 105x70x60mm, notou-se na superfície epidérmica lesão sobrelevada que mede $75 \times 45 \mathrm{~mm}$, constituída por tecido esbranquiçado, granuloso e friável. Tal lesão infiltrava na profundidade, comprometendo a hipoderme. Microscopia: Os cortes histológicos revelam pele apresentando neoplasia epitalial infiltrativa e ulcerada, constituída por arranjos císticos revestidos por múltiplas camadas de células epiteliais com núcleo aumentados de volume, hipercromáticos, com moderado pleomorfismo e amplos citoplasmas eosinofílicos. Notaramse também extensas áreas de necrose e freqüentes figuras de mitose. A neoplasia infiltrava planos profundos, inclusive tecido muscular esquelético. As margens cirúrgicas estavam livres. Diagnóstico: Carcinoma triquilemal (Fotos 5, 6 e 7).

\section{DISCUSSÃo}

O carcinoma triquilemal, também chamado tumor pilar triquilemal, constitui uma neoplasia cutânea pouco reconhecida no nosso meio. Tem ocorrência preferencial 


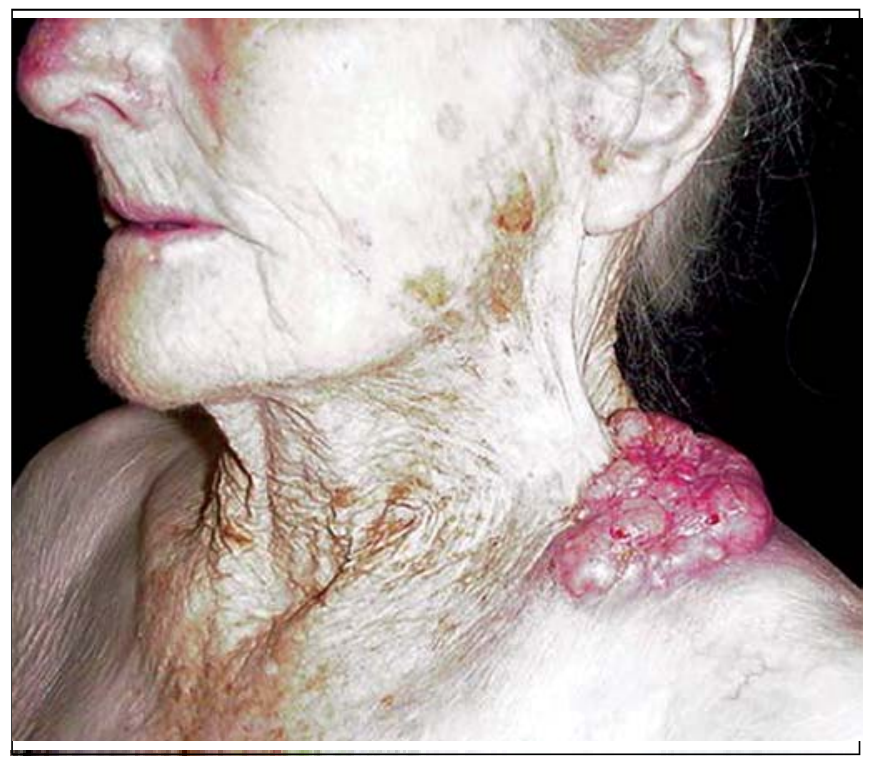

Foto 1. Foto ilustrativa da lesão. À ectoscopia: lesão localizada na região supra-clavicular esquerda, vegetante, ulcerada e com coloração avermelhada.

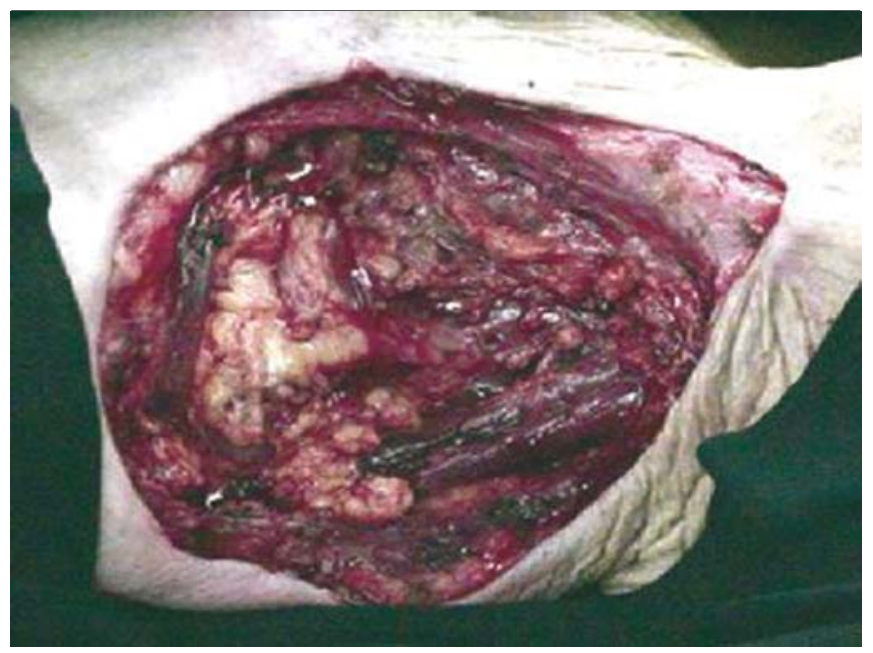

Foto 3. Foto após a excisão da lesão.

em pacientes do sexo feminino, com idade acima de 40 anos ${ }^{4}$. O local de manifestação habitual é o couro cabeludo, principalmente na pele exposta ao sol, como face e região cervical.

Caracteristicamente pode ser nodular ou em placas, ulcerado ou exofítico com queratose ou como crostas ${ }^{3}$. Geralmente apresenta-se com uma lesão solitária, medindo em média três centímetros seu maior diâmetro ${ }^{1}$. Usualmente tem sido encontrada com menos de um ano de evolução e com crescimento acelerado ${ }^{3}$.

Acredita-se que o carcinoma triquilemal é a forma maligna do triquilemoma. Apesar de especulativo, a

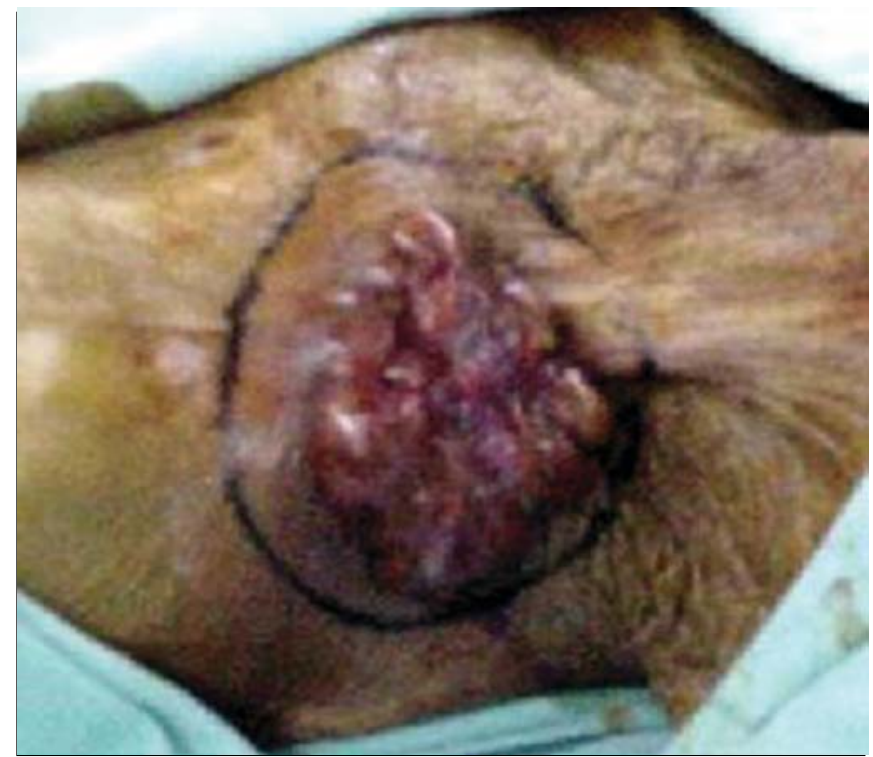

Foto 2. Foto da lesão antes do ato cirúrgico - as margens da excisão encontram-se delimitadas com azul de metileno.

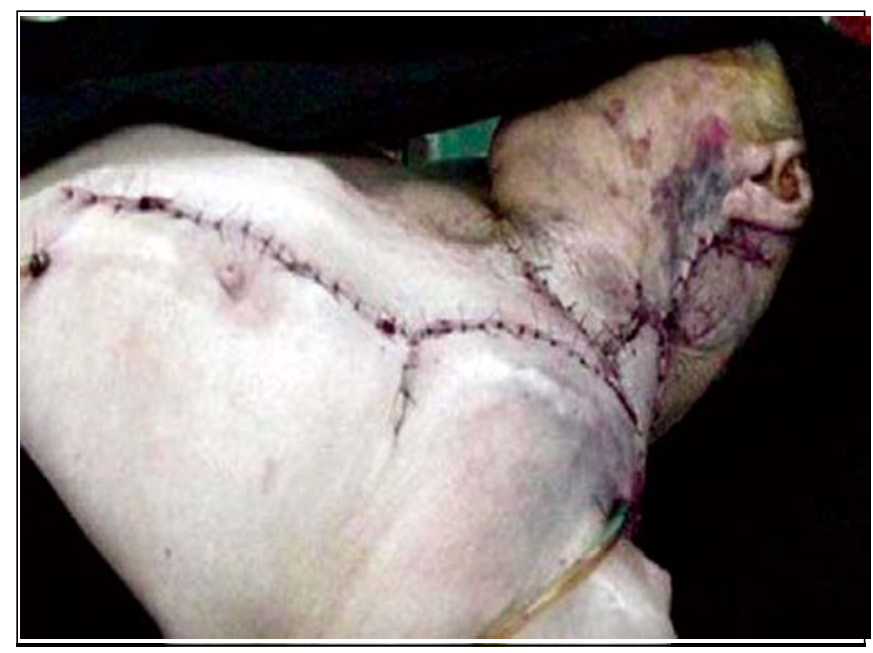

Foto 4. Foto após a reconstrução primária com rotação de retalho.

potencialidade da irradiação terapêutica em altas doses de lesões prévias bem como diagnóstica com Raios-X repetitivos também tem sido relacionada a esse tipo de carcinoma ${ }^{3}$. Existem ainda casos cujo aparecimento ocorreu na cicatriz de queimadura ${ }^{5}$ e em locais usualmente não expostos ao sol' $^{6}$.

Histologicamente, o TLC consiste de células com proliferação lobular central originado no folículo pilosebáceo composto por células malignas com potencial para mitose, porém com pouca agressividade. Os tumores podem invadir a derme ou intra-epitelialmente como células pagetóides e freqüentemente células linfocíticas e plasmáticas são vistas. 


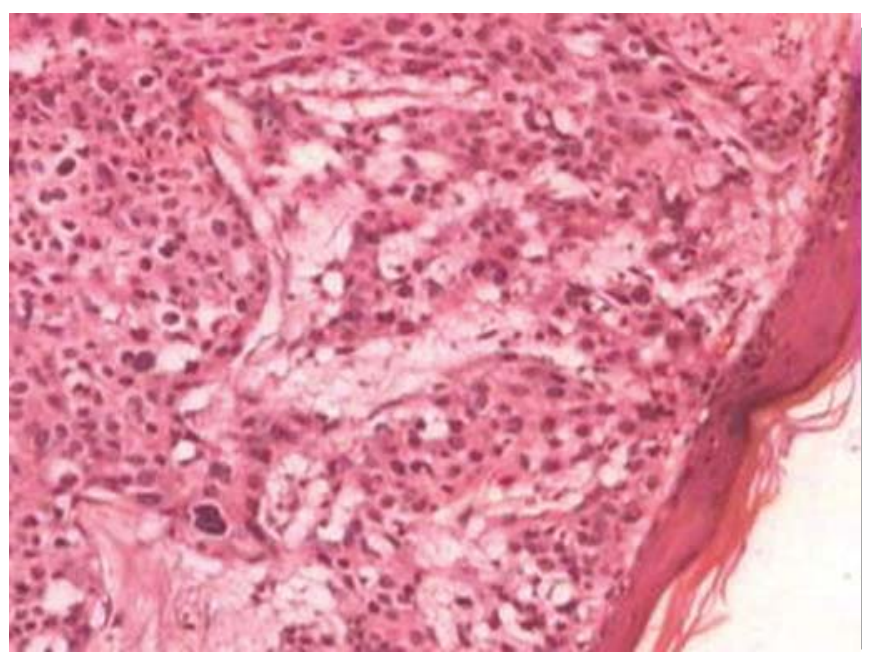

Figura 5. Micropatografia - HE - 40x. Pele com epiderme preservada, notando-se na derme neoplasia epitelial infiltrativa Carcinoma Triquilemal.

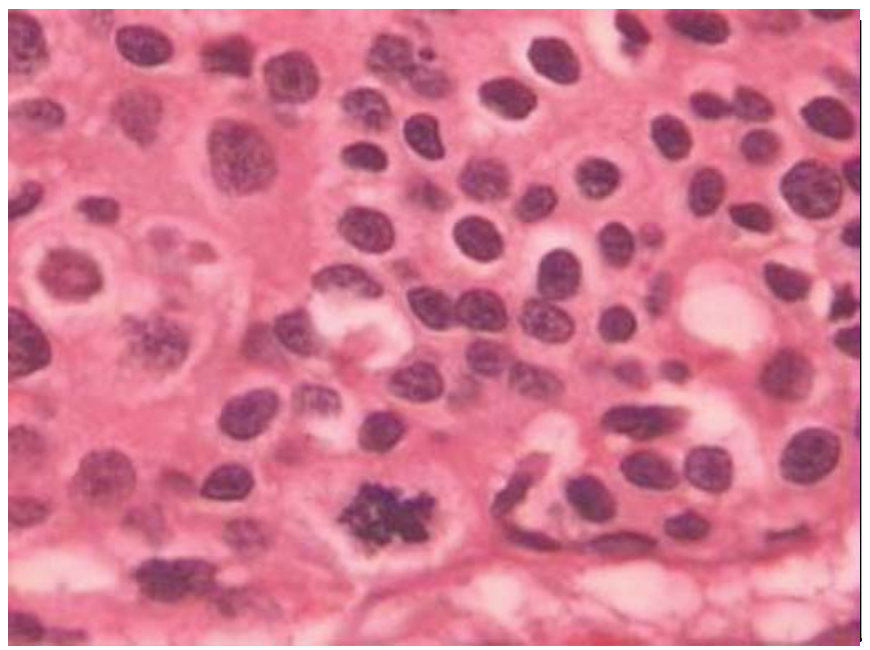

Figura 7. Micropatografia - HE - 400x. Blocos de células neoplásicas com moderada atipias nucleares, citoplasmas queratinizados. Notar figura de mitose às 6 horas - Carcinoma Triquilemal.

Apesar da sua estrutura histológica sugerir um certo grau de malignidade, o carcinoma triquilemal apresenta um curso indolente e raramente tem-se observado recorrência local ou metástases ${ }^{7-9}$.

Os carcinomas triquilemais devem ser distinguidos de outras lesões malignas, cada qual com suas características próprias e a melhor conduta a ser tomada.

O tratamento é cirúrgico, com ampla excisão da lesão e acompanhamento periódico, não há necessidade de terapia adjuvante.

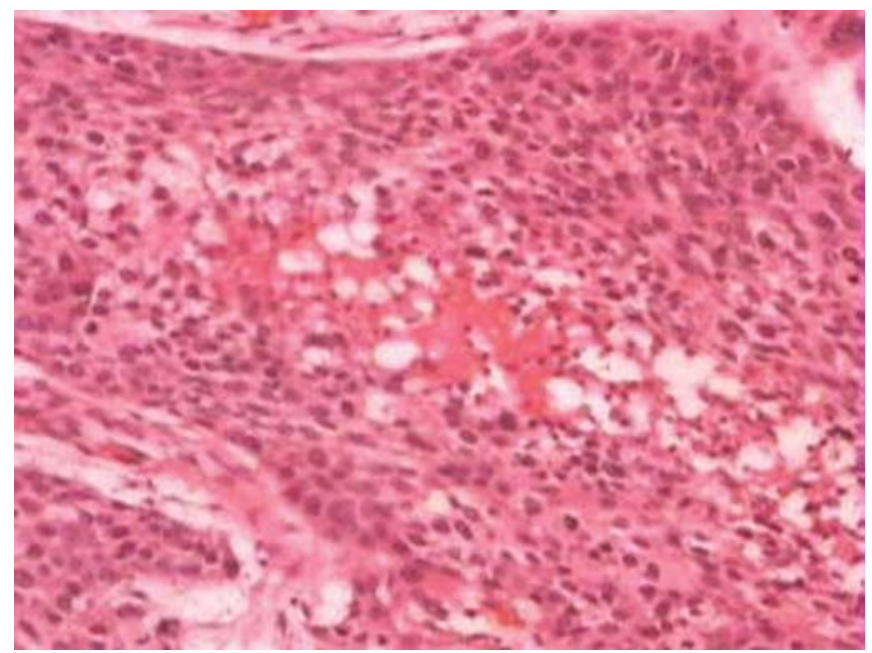

Figura 6. Micropatografia - HE - 40x. Neoplasia formando blocos sólidos alongados, crescendo em direção a derme e com necrose central - Carcinoma Triquilemal

\section{COMENTÁRIO FINAL}

Carcinoma triquilemal é uma neoplasia cutânea pouco encontrada no nosso meio. Deve ser pensada diante de um paciente feminino, com idade acima de 40 anos, que apresenta uma lesão em área da pele exposta ao sol, com características de massa vegetante simulando malignidade. Porém seu curso lento, índice mitótico baixo, rara recorrência local e metástases, nos tranqüilizam, sendo o tratamento exclusivamente cirúrgico.

\section{REFERÊNCIAS BIBLIOGRÁFICAS}

1. Barnhill RL et al. Textbook of Dermatology. United States of America. Mc Graw-Hill Company, Inc.; 1998. p.613-4.

2. Mckee $\mathrm{P}$ et al. Pathology of the Skin. $2^{\underline{a}}$ ed. Barcelona, Spain: Mosby-Wolf; 1996. 15.21-15.22.

3. Chan KO et al. Multiple tumor presentation of trichilemmal carcinoma. Br J Plast Surg 1999; 52(8): 665-7.

4. Maciel RARS et al. Tumor pilar triquilemal: estudo crítico de um caso peculiar e revisäo de literatura. An brasdermatol 1985; 60(2):81-6.

5. Ko $\mathrm{T}$ et al. Trichilemmal carcinoma developing in a burn scar: a report of two cases. J Dermatol 1996; 23(7): 463-8.

6. Dekio S, Funaki M, Jidoi J, Mihara M. Trichilemmal carcinoma on the thigh: report of a case. J Dermatol 1994; 21(7): 494-6.

7. Reis JP et al. Tricholemmal carcinoma: a review of 8 cases. J Cutan Pathol 1993; 20: 44-9.

8. Boscaino A et al. Trichilemmal carcinoma: a study of seven cases. J Cutan Pathol 1992; 19: 94-9.

9. Swanson PE et al. Tricholemmal carcinoma: clinicopathologic study of 10 cases. J Cutan Pathol 1992; 19: 100-9. 